\title{
Investigation of Polycyclic Aromatic Hydrocarbons in Seawater Collected From Lebanese Coast
}

\author{
BERNA HAMAD ${ }^{1}$, INAS EL HASSAN ${ }^{1}$, FATIMA TALEB ${ }^{1}$, \\ MOHAMAD TABCHEH ${ }^{1}$, HANNA El-NAKAT ${ }^{2}$ and AHMAD ALLOUCH ${ }^{1 *}$ \\ ${ }^{1}$ Laboratory of Applied Chemistry (LAC), Faculty of Sciences III, Lebanese University, \\ P.O. Box 826, Tripoli, Lebanon \\ ${ }^{2}$ Department of Chemistry, Faculty of Sciences, University of Balamand, P.O. Box 100, \\ Tripoli, Lebanon \\ aallouch@ul.edu.lb
}

Received 23 January 2019 / Accepted 7 February 2019

\begin{abstract}
Polycyclic aromatic hydrocarbons ( luorine ne, acenaphtene, acenaphtelene, luorine, phenanthrene, anthracene, fluoranthene, pyrene, benzo[a]anthracene, chrysene, benzo[b]fluoranthene, benzo[k]fluoranthene, benzo[a]pyrene, dibenzo[a,h]anthracene, benzo[g,h,i]perylene and indeno[1,2,3c,d]pyrene) have been analyzed in seawater sampled on five sites of the Lebanese coast (Tripoli, Akkar, Batroun, Jbeil and Beirut) between February and June 2018. HPLC technique, with UV detector, following liquid-liquid extraction, is the method chosen to detect, analyze and quantify these compounds, because of its specificity and its sensitivity.
\end{abstract}

Keywords: Polycyclic aromatic hydrocarbons, Extraction methods, Seawater, HPLC

\section{Introduction}

Scientists all around the world have shown interest in studying the pollution of polycyclic aromatic hydrocarbons (PAHs) to assess the potential impact of anthropogenic activities on aquatic environments because their occurrence in water is closely tied to urban activities. Many PAHs possess mutagenic and carcinogenic properties ${ }^{1}$. PAHs are consequently listed by the US Environmental Protection Agency (EPA) as priority pollutants ${ }^{2}$.

Polycyclic aromatic hydrocarbons (PAHs) constitute a large group of organic pollutants which includes more than 200 chemical compounds. These compounds are in the form of mixtures. PAHs are built from at least two aromatic rings without any substituents. They are hardly soluble in water and have high affinity for sorption on the surface of solid materials $^{3,4}$.

PAHs are formed by incomplete combustion of organic matter such as fossil fuels, forest fires, domestic sewages, animal droppings, wood burning, traffic engines and other organic materials ${ }^{5,6}$. As well, the derivatives from the digenesis of crude oil and organic matter 
under anoxic conditions are considered amongst the main PAHs sources ${ }^{7,8}$. PAHs are widely distributed in the atmosphere, water, soils and sediments ${ }^{9,10}$. Considerable efforts have been devoted to the analysis of PAHs in a variety of environmental samples ${ }^{11,12}$.

The presence of high concentrations of PAHs in the environment is also connected with ecological and economical issues. Long-term contamination may lead to permanent changes in local ecosystems, and may have influence on the reduction of the agricultural crops productivity $^{13-17}$.

The european water framework directive has specified that the sum of the concentrations of all PAHs in water for human use must not exceed $0.1 \mu \mathrm{g} . \mathrm{L}^{-1}$. Moreover, the concentration of benzo[a]pyrène must be limited ${ }^{18}$ to $0.01 \mu \mathrm{g} . \mathrm{L}^{-1}$.

The utilization of High performance liquid chromatography (HPLC), with ultraviolet (UV) detection, has long been a common practice in the analysis of PAHs. This technique, which involves liquid-liquid extraction and preconcentration of PAHs from seawater, has proven ideally suitable for the nonvolatile and thermolabile $\mathrm{PAHs}^{19-21}$.

Lebanon, a small country with a dense population of about 4 million people, faces a multitude of environmental stresses among which are deforestation, traffic congestion and the deterioration of water quality by land.

In this paper, we report on the chromatographic identification and quantification of the sixteen PAHs listed as US EPA priority pollutants compounds in five samples of seawater of the Lebanese coast.

\section{Experimental}

To compare seawater contamination in different locations, samples were collected at different stations as depicted in the map of Lebanon, Figure 1.

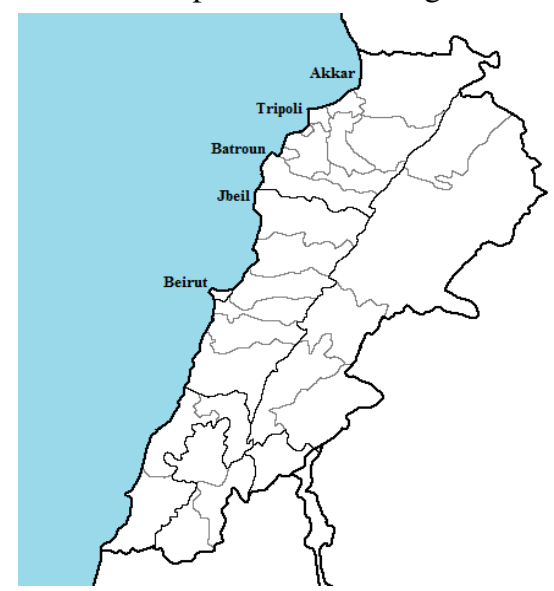

Figure 1. Map showing the sampling locations in Lebanon

\section{Sampling procedure}

Samples were collected, on weekly basis, from the five sites in the period that extended between February and June 2018 using 1L amber glass bottles. To minimize contamination, all glassware was cleaned with detergent solution, rinsed with distilled water, heated in an oven at $500{ }^{\circ} \mathrm{C}$ for eight hours to combust traces of organic matter, and finally rinsed with dichloromethane. Sample extraction was performed within $24 \mathrm{~h}$. 


\section{Materials and reagents}

All chemicals were purchased from Sigma-Aldrich Chemical Company. Solvents were of the highest grade of purity commercially available and were used without further purification. The PAH mixture solution containing 16 USEPA priority PAHs standard [naphthalene (Nap), acenaphthylene (Acy), acenaphthene (Ace), fluorine (Fle), phenanthrene (Phe), anthracene (Anth), fluoranthene (Fla), pyrene (Pyr), benzo[a]anthracene (BaA), chrysene (Chr), benzo[b]fluoranthene $(\mathrm{BbF})$, benzo[k]fluoranthene $(\mathrm{BkF})$, benzo[a]pyrene $(\mathrm{BaP})$, indeno[1,2,3-cd]pyrene (Ind), dibenz[a,h]anthracene (DBA) and benzo[g,h,i]perylene (BgP)], each at $10 \mu \mathrm{g} \cdot \mathrm{mL}^{-1}$ in acetonitrile, was purchased from Sigma-Aldrich. In order to exclude impurities before use, analytical-grade anhydrous $\mathrm{Na}_{2} \mathrm{SO}_{4}$ was used.

\section{Extraction of PAHs}

The general overall method used has been described in the literature ${ }^{20}$. The initial $1 \mathrm{~L}$ water sample, to be analyzed, was equally divided into two $500 \mathrm{~mL}$ fractions. For each fraction, two successive extractions were carried out. Each extraction involved the addition of $100 \mathrm{~mL}$ of dichloromethane while letting the mixture shack for one hour with a stirring bar on a magnetic agitator. The mixture was then extracted using a separating funnel. All extracts, combined to a total of $400 \mathrm{~mL}$ of dichloromethane, were dried with anhydrous $\mathrm{Na}_{2} \mathrm{SO}_{4}$ and concentrated by rotary evaporation to a $1 \mathrm{~mL}$ residue liquid for HPLC analysis.

\section{Adsorption of PAHs on activated carbon}

Seawater treatment was carried out by adsorption on powdered activated carbon to test its effectiveness in removing PAHs that exist there. However, after filtering the sample, we added $3 \mathrm{~g}$ of powder activated carbon. The mixture was stirred for 2 hours at room temperature. We then carried out two consecutive filtrations of the mixture to get rid of the activated carbon. This was followed by extraction with dichloromethane then by concentration on a rotary evaporator according to the same procedure already described. The resulting solution was later admitted for HPLC analysis.

\section{Instrumentation}

Chromatographic studies were performed on a Schimadzu HPLC system (UFLC) equipped with a thermostated-column device, a degasser and a variable-wavelength UV detector. The column used for analytical HPLC was C-18 $(150 \mathrm{~mm} \times 4.6 \mathrm{~mm})$. The mobile phase was a mixture of acetonitrile/water $(60 / 40 \%)$ with a flow rate of $1 \mathrm{~mL} / \mathrm{min}$. The wavelength of UV detector was set at $254 \mathrm{~nm}$ and the column was operated at room temperature. The injection volume was $20 \mu \mathrm{L}$.

\section{Dosage of PAHs detected}

The second part of the study consisted of determining the concentration of each PAH identified in the samples obtained from the five locations. For this purpose, a series of dilutions of the standard stock solution $(2,4,6$ and $8 \mu \mathrm{g} / \mathrm{mL})$ was prepared. The corresponding chromatograms recorded clearly showed the variation of the surface of each peak as a function of the concentration prepared.

\section{Results and Discussion}

Due to the wide variety of PAHs and the cost of dosages, only 16 have been detected. These are mentioned as priority pollutants by the US Environmental Protection Agency in the $80 \mathrm{~s}^{18}$. HPLC reverse polarity has proven to be one of the most efficient identification and 
separation techniques and has been, accordingly, commonly used in chemical analysis laboratories. It allows the identification, separation and dosing of PAHs in different samples analyzed. Its high precision, high separation speed, high reliability and the lowering of the detection threshold, made it possible to search for traces. UV detection has been, as well, commonly used to identify PAHs based on their previously defined retention time using standard solutions at the same conditions.

The column chosen was the $\mathrm{C}-18$. The mobile phase used was a water/acetonitrile mixture, 40/60\%. It must have sufficient eluent strength to elute the most hydrophobic PAHs. In our experiments, a total duration of $40 \mathrm{~min}$ was needed for the analysis. The first step consisted in passing the 16 USEPA priority PAHs standards in HPLC. The goal of this step was to obtain the chromatogram and, accordingly, the characteristics (retention time) of each of the various PAHs existing in the standard; as references for further analysis.

The second step was to pass the samples of seawater, obtained from the five locations, under the same conditions. The presence of several PAHs in these samples, from the various locations, was confirmed by reflecting on the standard, simply by comparing their corresponding chromatograms. Figure 2 represents the chromatograms obtained by HPLC of PAHs detected in seawater of Tripoli and Jbeil. The retention time and area of the peak for each of the detected PAHs for each location are presented in Table 1.

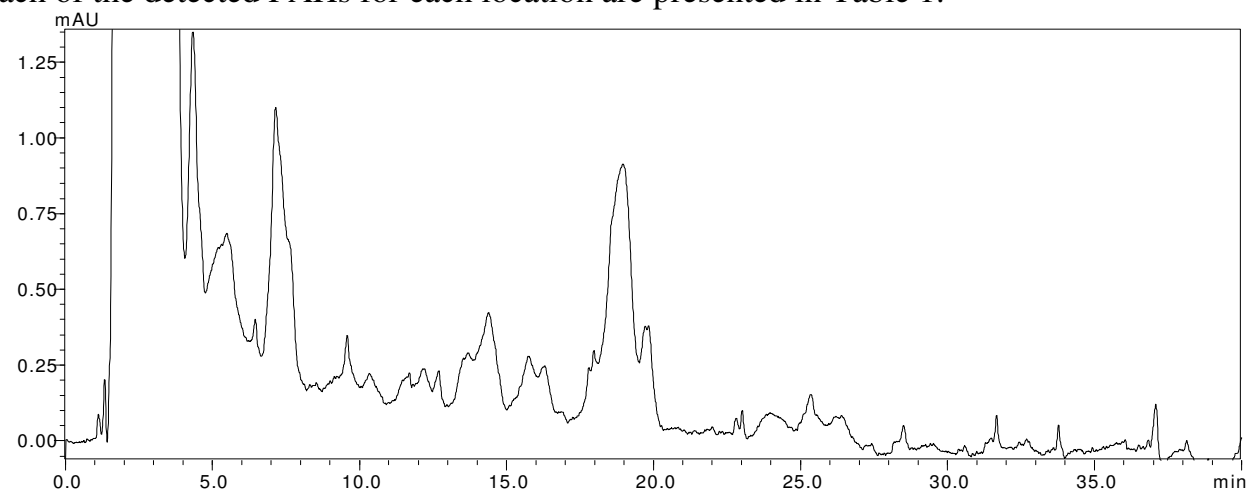

(a)

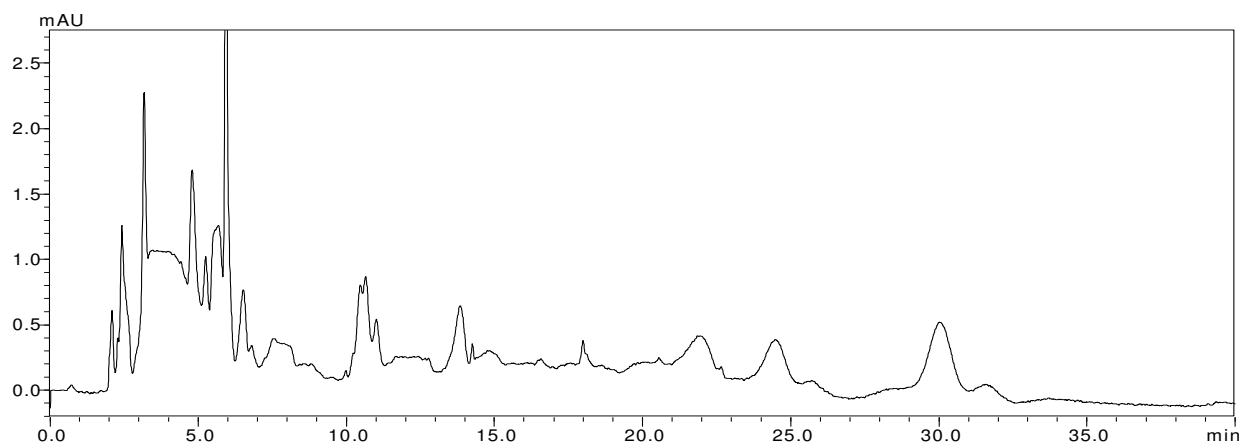

(b)

Figure 2. Chromatograms obtained by HPLC of PAHs detected in seawater of a) Tripoli and b) Jbeil. Chromatographic conditions: Schimadzu HPLC system, C-18 (150 mm×4.6 mm) column, mobile phase: $40 / 60 \%$ water-acetonitril, flow rate: $1 \mathrm{~mL} / \mathrm{min}$, wavelength: $254 \mathrm{~nm}$ 
Table 1. Characteristics of the PAHs detected in the five seawater samples

\begin{tabular}{cccc}
\hline Site & Compound & Retention Time/min & Area \\
\hline \multirow{4}{*}{ Akkar } & Naphtalene & 5.5 & 3478 \\
& Acenaphtylene & 6.0 & 10257 \\
& Acenaphtene & 7.8 & 45766 \\
& Anthracene & 12.7 & 18421 \\
\hline & Naphtalene & 5.6 & 10375 \\
& Acenaphtene & 8.0 & 44875 \\
Tripoli & Fluorene & 9.5 & 1678 \\
& Fluorenthene & 14.4 & 12112 \\
& Pyrene & 15.7 & 4517 \\
& Benzo(a)anthracene & 19.7 & 4458 \\
& Chrysene & 21.5 & 20442 \\
& Benzo(b)fluoranthène & 25.4 & 1669 \\
\hline \multirow{4}{*}{ Batroun } & Naphtalene & 5.4 & 14011 \\
& Acenaphtylene & 6.5 & 9843 \\
& Fluorenthene & 14.3 & 21038 \\
\hline \multirow{4}{*}{ Jbeil } & Naphtalene & 5.6 & 15894 \\
& Acenaphtylene & 6.2 & 32426 \\
& Phenanthrene & 11 & 4924 \\
& Chrysene & 21.8 & 11617 \\
\hline \multirow{4}{*}{ Beirut } & Naphtalene & 5.4 & 27734 \\
& Acenaphtylene & 6.2 & 65388 \\
& Acenaphtene & 8.0 & 8643 \\
& Pyrene & 15.5 & 2212142 \\
& Phenanthrene & 11.1 & 350786 \\
& Anthracene & 12.9 & 8677 \\
\hline
\end{tabular}

In the third step of the study, the concentration of each $\mathrm{PAH}$, as detected in the different locations, was calculated. The method used is based on the graphical representation of curves, obtained by means of the experimental measurements using Origin 6.0 professional program, Figure 3. The results are summarized in Table 2.

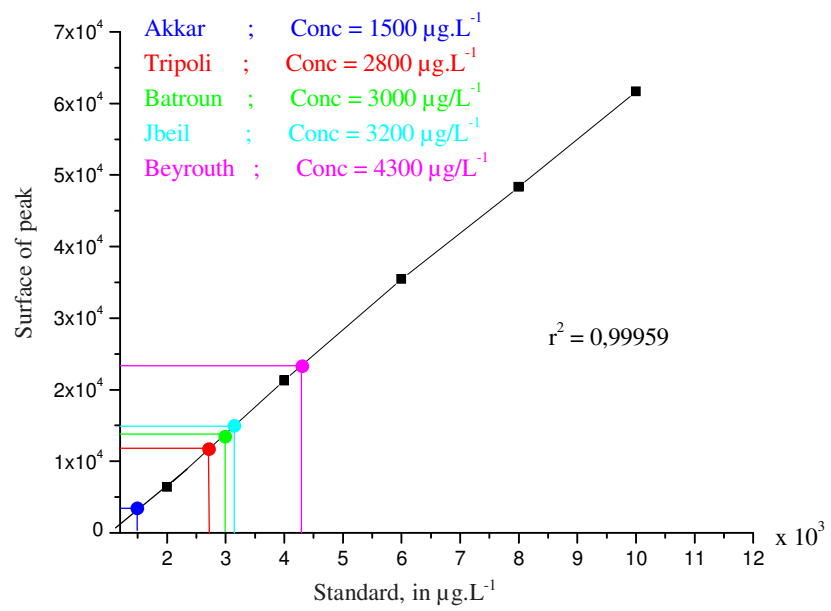

Figure 3. Calibration curve for the dosage of Naphtalene 
Table 2. Concentration of PAHs detected in the five seawater samples in $\mu \mathrm{g} . \mathrm{L}^{-1}$ before treatment by activated carbon

\begin{tabular}{llllll}
\hline \multirow{2}{*}{ PAH Detected $/\left(\mathrm{gL}^{-1}\right)$} & $\begin{array}{l}{[\mathrm{PAH}] /} \\
\text { Akkar }\end{array}$ & $\begin{array}{l}{[\mathrm{PAH}] /} \\
\text { Tripoli }\end{array}$ & $\begin{array}{l}{[\mathrm{PAH}] /} \\
\text { Batroun }\end{array}$ & $\begin{array}{l}{[\mathrm{PAH}] /} \\
\text { Jbeil }\end{array}$ & $\begin{array}{l}{[\mathrm{PAH}] /} \\
\text { Beyrouth }\end{array}$ \\
\hline Naphtalene & 1500 & 2800 & 3000 & 3200 & 4300 \\
Acenaphtylene & 2800 & - & 2400 & 5200 & 9700 \\
Acenaphtene & 3150 & 3500 & - & - & 1500 \\
Fluorene & - & nd & - & - & - \\
Fluoranthene & - & nd & 6500 & - & - \\
Pyrene & - & nd & - & - & 4300 \\
Anthracene & 1500 & - & - & - & 1200 \\
Phenanthrene & - & - & - & 2400 & 4300 \\
Chrysene & - & 1700 & - & nd & - \\
Benzo(a)anthracene & - & 1400 & - & - & - \\
Benzo(b)fluoranthene & - & 1000 & - & - & - \\
$\sum$ & 8950 & 10400 & 11900 & 10800 & 25300 \\
\hline
\end{tabular}

nd: not determined

As shown in Table 1 and Table 2, the results obtained revealed the presence of 4 PAHs in Akkar seawater (naphthalene, acenaphthylene, acenaphthene and anthracene) of $\Sigma=8950 \mu \mathrm{g} . \mathrm{L}^{-1}$, $8 \mathrm{PAHs}$ in the seawater of Tripoli (naphthalene, acenaphthene, fluorene, fluoranthene, pyrene, benzo (a) anthracene, chrysene and benzo (b) fluoranthene) of $\Sigma=10400 \mu \mathrm{g} . \mathrm{L}^{-1}, 3$ PAHs in Batroun seawater (naphthalene, acenaphthylene and fluoranthene) of $\Sigma=11900 \mu \mathrm{g} . \mathrm{L}^{-1}$, 4 PAHs in Jbeil seawater (naphthalene, acenaphthylene, phenanthrene and chrysene) of $\Sigma=$ $10800 \mu \mathrm{g} . \mathrm{L}^{-1}$ and 6 PAHs in seawater of Beirut at high concentrations of $\Sigma=25300 \mu \mathrm{g} . \mathrm{L}^{-1}$ (naphthalene, acenaphthylene, acenaphthene, phenanthrene, anthracene and pyrene). These results show seawater contamination with PAH concentrations far exceeding environmental standards and specifications.

The treatment of the samples by activated carbon showed an almost negligible effect in the samples where the levels of PAHs was low (Tripoli, Akkar, Batroun and Jbeil). However, in the case of high PAHs concentrations, as found for samples taken from Beirut, a surprising positive effect (up to $70 \%$ reduction) has been detected; an indication that activated carbon has significantly eliminated PAHs. The relative contribution of each individual PAH to the total PAHs concentration has been determined for the five sampling sites and are presented in Figure 4.
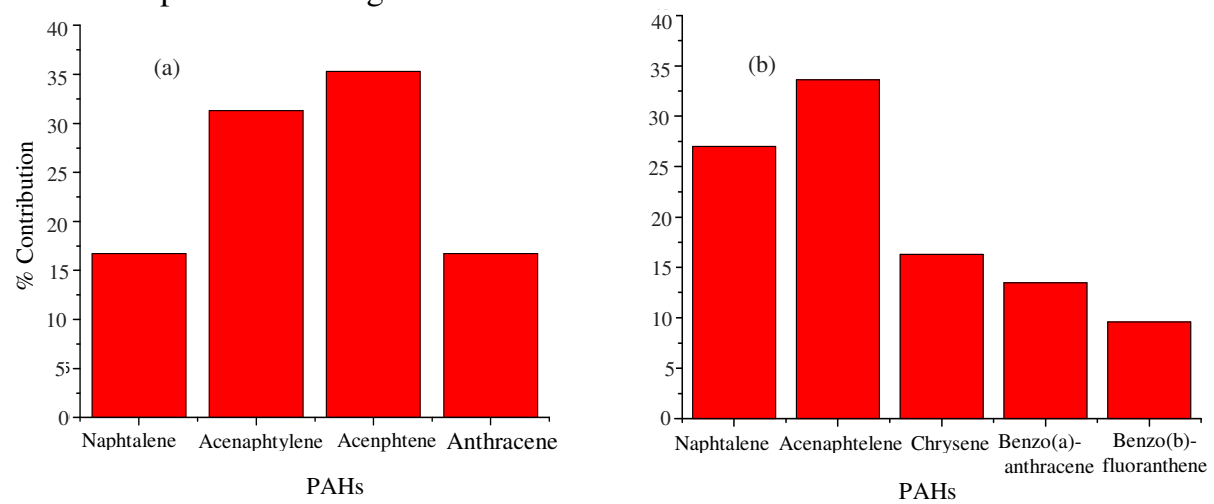

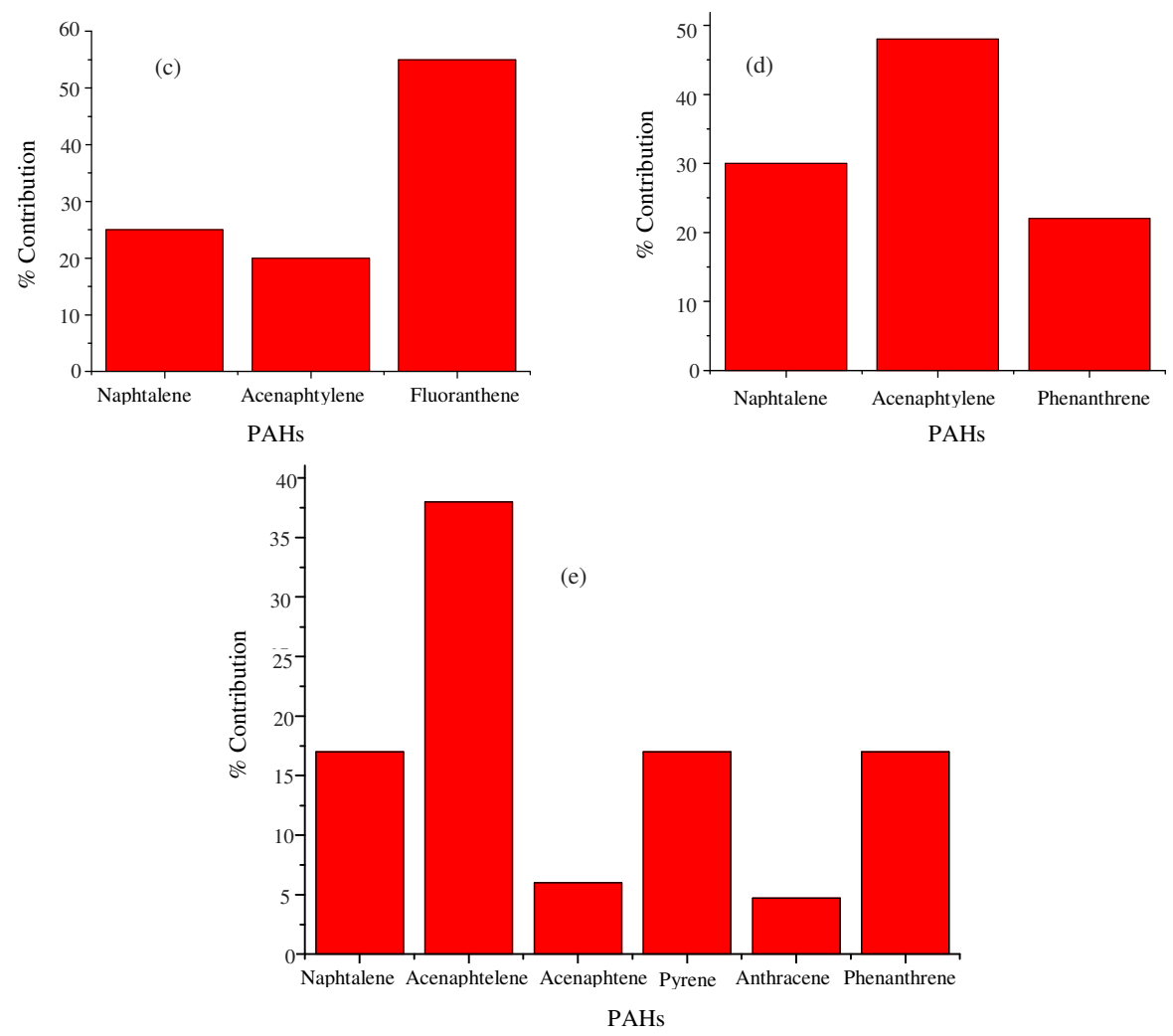

Figure 4. Contribution of each individual PAH to the total PAHs in seawater analyzed at a) Akkar, b) Tripoli, c) Batroun, d) Jbeil and e) Beirut

Water samples from the five areas exhibit similar PAH patterns, with a predominance of two- three-ring PAH compounds. The results obtained show high PAHs contaminations in the seawater of all samples. This, therefore, calls for effective water treatment and efficient purification in order to get rid of any present contamination.

\section{Reproducibility}

The reproducibility of the methods has been determined by replicate analysis of three separate samples. The results have proven satisfactory with standard deviations not exceeding $2 \%$ and the correlation coefficients were greater than 0.999 for all the analyzed compounds.

\section{Conclusion}

The work presented in this paper focused on the study and the analysis of the quality of seawater on the Lebanese coast that extends from Beirut going north till the boarders with Syria.

For this purpose, five seawater samples (Tripoli, Akkar, Batroun, Jbeil and Beirut) were processed. The procedure applied consists of carrying out the following steps: a liquid-liquid extraction with dichloromethane of each sample and an analysis on reverse phase HPLC. The chromatograms thus recorded reveal the presence of several peaks each corresponding to a given PAH. The comparison of the results obtained with those provided by the marketed standard made it possible to identify each PAH present and to quantify it. 
This study showed that the analyzed seawater samples were contaminated by PAHs. This contamination varied in terms of the detected PAHs and the concentration of each contaminant between the studied regions. It is almost impossible to relate the detected contaminant to its source in each of the sampling regions. In other words, it is not possible to relate a contaminant to the site of detection. In addition to the contamination, of all types, caused by the immediate location from which sampling took place, the uncontrolled dumping of untreated waste, agricultural or industrial waters into rivers can carry with it the detected contaminants from far distances to the same spot where sampling was done. In addition, the many sea currents and the change of direction of such currents with time play an important role in this respect.

As well, this study aimed at investigating the effectiveness of activated carbon (AC) in removing PAHs contaminants from the sampled seawater. The results obtained showed a negligible effect in the samples of Tripoli, Akkar, Batroun and Jbeil and a positive effect for samples taken from Beirut. This indicates that activated carbon has significantly eliminated PAHs.

The results of this work constitute the bases of a work to be pursued for a more in-depth study which aims at finding more effective adsorbent agents than the activated carbon to eliminate as much as possible the PAHs presents whatever their concentrations.

\section{Acknowledgement}

The authors would like to thank the management committee of scientific research at the Lebanese University.

\section{References}

1. Menzie C A, Potocki B B and Santodonato J, Environ Sci Technol., 1992, 26(7), 1278-1284; DOI:10.1021/es00031a002

2. Delhomme O, Rieb E and Millet M, Polycyclic Aromatic Compounds, 2008, 28, 472485; DOI: $10.1080 / 10406630802377898$

3. Czarnomski K, Scientific Publisher Gabriel Borowski, 2008, 15-18.

4. Lerda D, Polycyclic aromatic hydrocarbons factsheet, Belgium JRC, 2010.

5. Yunker M B, Macdonald R W, Vingarzan R, Mitchell R H, Goyette D and Sylvestre S, Org Geochem., 2002, 33(4), 489-515; DOI:10.1016/S0146-6380(02)00002-5

6. Chen F, Tan M, Ma J, Zhang S L, Li G and Qu J F, J Hazard Mater., 2016, 302, 250261; DOI:10.1016/j.jhazmat.2015.09.068

7. $\quad$ Lima A L, Farrington J W and Reddy C M, Environ Forensics, 2005, 6(2), 109-131; DOI:10.1080/15275920590952739

8. Ekpo B O, Fubara E P, Ekpa O D and Marynowski H L, ARPN J Earth Sciences, 2012, 1(1), 9-20.

9. Li J, Shang X, Zhao Z, Tanguay R L, Dong Q and Huang C, J Hazard Mater., 2010, 173(1-3), 75-81; DOI:10.1016/j.jhazmat.2009.08.050

10. Kim K H, Jahan S A, Kabir E and Brown R J, Environ Int., 2013, 60, 71-80; DOI:10.1016/j.envint.2013.07.019

11. Bjorseth A, Handbook of Polycyclic Aromatic Hydrocarbons, Dekker, New York, NY, 1983, 1.

12. Lee M L, Novotny M V and Bartle V D, Analytical Chemistry of Polycyclic Aromatic Compounds, Academic Press, New York, NY, 1981.

13. Oleszczuk P, Ecol Chem Engg., 2007, 14(S2), 185-198. 
14. Chen J, Wong M H, Wong Y S and Tam N F Y, Marine Pollution Bulletin, 2008, 57(6-12), 695-702; DOI:10.1016/j.marpolbul.2008.03.013

15. Wammer K and Peters C, Environ Sci Technol., 2005, 39(8), 2571-2578; DOI:10.1021/es048939y

16. Nisbet I C Tand LaGoy P K, Regulat Toxicol Pharmacol., 1992, 16(3), 290-300; DOI:10.1016/0273-2300(92)90009-X

17. Zhang Y and Wang J, China Environ Monit Assess., 2011, 182, 535-543.

18. a) Pimsee P, Sablayrolles C, Montréjaud-Vignoles M, Guyomarch J, Lesage N and De Caro P, J Env Protection, 2014, 5, 681-693; DOI:10.4236/jep.2014.58069; b) EU (2000) Directive 2000/60/EC of 23 October 2000 Establishing a Framework for Community Action in the Field of Water Policy. (22 December 2000). Official Journal of the European Communities, L327, 1-37.

19. Das B S and Lawrence J F, Humana Press, Clifton, New Jersey, 1984, 19.

20. Manoli E and Samara C, Chromatographia, 1996, 43(3-4), 135-142; DOI:10.1007/BF02292941

21. Longbottom J E and Lichenberg J J, Methods of Organic Chemical Analysis of Municipal and Industrial Wastewater, USEPA., July 1982, report No EPA-600/4-82-057. 